\title{
OS ESTÁGIOS DA PRIMEIRIDADE
}

\author{
Lauro Frederico Barbosa da Silveira* \\ lfbsilv@terra.com.br
}

Peirce coloca-se na tradição dos autores que procuram conferir às ciências um quadro sistemático de distribuição e hierarquização. Tomando a Matemática como a mais genuína ciência formal, confere-lhe o lugar fundante de todo conhecimento . Não há ciência onde não houver matemática - poderia Peirce tomar para si esta lapidar afirmação de Kant. De outro lado, no extremo oposto do quadro geral das ciências encontrar-se-ão aquelas ciências cujos objetos, dada sua máxima particularidade, mais próximos estão da existência brutalmente experimentada pelos sujeitos. Encontram-se aí as ciências práticas, as artes e as habilidades técnicas.

No centro de um tal espectro, certamente localizar-se-á a metafísica que como a mais concreta das ciências gerais, inaugura, como seu limiar, aquelas ciências que se dedicam a investigar os modos especiais com que os fenômenos se apresentam.

Ciência que confere a um Mundo as formas que as aparências apresentam e que a conduta deve assumir ao - com elas - interagir, a metafísica tem um caráter estritamente hipotético não por ser meramente formal mas por conjeturar sobre como deveria ser a realidade para acolher em si as formas idealizadas originalmente pela matemática, inclusive em sua função lógica; as aparências e os fins que motivam e movem condutas.

A metafísica conclui, como ciência do contínuo e da lei em sua natureza própria, tudo que cabe às ciências do dever ser, ou daquilo que é essencial para a constituição de todo ser. Inicia, por outro lado, a investigação dos modos de ser sem deixar que um hiato, por mínimo que seja, rompa a continuidade entre as ciências construtoras das formas, as ciências determinantes da conduta, e as diversas ciências especiais que caracterizarão a conduta diante desta ou daquela

\footnotetext{
* Professor no Programa de Pós-Graduação e Filosofia da UNESP, campus de Marília e do Programa de Mestrado do Centro Universitário "Eurípides" de Marília. Marília, SP. 
classe de fenômenos. Pressupõe a validade universal da matemática e da lógica e a implicação de uma conduta que, pertinente ao universo dos fenômenos, admira-os, elege alguns como objeto de seu especial interesse e representa o caminho que melhor a conduzirá, no futuro, a se relacionar com aquela classe de fenômenos.

Da matemática às ciências práticas o caminho sempre se fará da potencialidade positiva à restrição e diversificação desta mesma realidade. Toda a potência do pensamento é de natureza eidética, pertinente, dirá Peirce, ao Mundo interior proposto por Platão. Toda diversificação predicará as idéias a sujeitos que as concretizem, as façam atuar e, conseqüentemente, limitaremse mutuamente. Os sujeitos de predicação comporão os universos e, estes, o mundo exterior ou quase-exterior. As próprias idéias serão experimentadas como objetos por via de abstração e substantivação, fazendo com que integrem também o mundo exterior sob a forma de universos que lhe sejam característicos. A mente é, para Peirce, predicativa de todos os universos possíveis.

Primeiro, portanto, são as idéias; em segundo lugar, os existentes como concreções e delimitações de idéias e em terceiro lugar, decorrentes geneticamente de ambos mas logicamente os intermediando, o contínuo e a lei, generalizam os confrontos entre existentes prognosticando as qualidades que darão ensejo a futuras experiências, e determinando a conduta tendo em vista tais experiências.

A interrelação do primeiro, do segundo e do terceiro não se limita a ordenar este quadro amplo das diversas ciências. Subdivide-as em um nível de maior detalhamento em ciências da descoberta que propõem as possíveis explicações para os fenômenos e, conseqüentemente, conferem toda potência à representação do real, em ciências da revisão, que verificam a adequação da teoria aos dados a que se aplicam e em ciências práticas que, como já se viu, generalizam o procedimento científico a toda classe de fenômenos distributivamente considerada, e diversificando-se na interação mais próxima do objeto e da conduta na experiência. As ciências da descoberta são, pois, caracterizadas pela primeiridade; o teste da revisão, pela secundidade e as práticas, pela terceiridade.

Se nos voltarmos para a classe das ciências da descoberta, novamente a primeiridade, a secundidade e a terceiridade irão exercer seu papel classificador: a fenomenologia, como ciência ingênua das meras aparências, permite que o universo da experiência, primeiro e primordial sujeito de qualquer predicação, apresente-se em toda sua espontaneidade, sem que a ele caiba estabelecer qualquer restrição, mas somente caracterizá-lo pelas idéias que o distinguem: e estas serão, para Peirce, precisamente, a potencialidade, denominada primeiridade, a existência, ou secundidade e a generalidade ou lei, como terceiridade. Como ciência da experiência possível, a Fenomenologia será caracterizada, entre as ciências da descoberta, pela relação de primeiridade. 
Em vista de fins que não lhes são intrínsecos, as ciências normativas, ou ciências norteadoras da conduta, investigarão, do ponto de vista desta última, a interação com o real que, fenomenologicamente, se apresenta. Como relação a um outro, têm por fulcro a experiência e, portanto a existência. Restringem, pois, o domínio da potencialidade do fenômeno, àquele em que estará implicada a conduta. Uma tal restrição, que é fundamentada no fato da interação e da negação relativa de um mesmo por um outro, traz a marca da secundidade.

Considerar, finalmente, os possíveis fundamentos ontológicos das aparências e de seu poder de determinar a conduta, sugerindo qual seria a natureza última do real; o fundamento último de toda atração de uma conduta, na forma do admirável e do bem; e o fundamento ontológico das leis que representam o real e determinam a conduta diante de experiências futuras, é o objeto da metafísica como mediadora última, ao nível da representação entre o trabalho formal sobre as aparências e as efetivas no âmbito da realidade, objeto que são das diversas ciências especiais. Ao nível, pois, das ciências filosóficas, na metafísica predominam as relações de terceiridade.

Considerando-se agora as ciências normativas, na estética, cujo objeto é o admirável que se impõe à mente pela unidade de suas qualidades e que a afeta por mera afeição, na sintonia que estabelece entre as qualidades do objeto e as do sujeito e cujo papel para a conduta é de abrir-se à sua admiração, prevalecem, com efeito, as relações de primeiridade.

As relações de secundidade terão lugar a partir do momento em que as qualidades puderem interagir, diversificando-se segundo uma infinita gama de intensidades. Ocuparão cada vez mais o proscênio do que Peirce denominava o teatro das reações: - efetivamente as qualidades atuarão em choque uma com as outras, aparentemente fragmentando o universo das qualidades e fazendo predominar concreções impositivas no poder ser.

Finalmente, o que eram eventuais concreções tornam-se, com freqüência, hábitos de condutas conferindo primazia à efetivação de determinadas reações em detrimento daquelas que, em vez de se aglutinarem, se repeliam e se aniquilavam, voltando ao primordial de meras qualidades.

A atração de qualidades afins traduz-se em volição e em atração da conduta ao objeto de seu desejo. A ética é a ciência que investiga esta atração dos seres a seus fins.

A ciência da mediação que programa a conduta, para no futuro satisfazer seu desejo, é a lógica ou semiótica, terceira entre as ciências normativas.

No contínuo da realidade, o destino das qualidades em se tornarem leis é descrito em imagens de grande poesia num texto como o seguinte: 
Como pode ter derivado o contínuo? Decorreu ele, por exemplo, do ajuntamento de partes? Fundiram-se pontos separados, ou o quê?

Debrucando-nos sobre o curso da lógica como um todo, vemos que ele procede da questão à resposta - do vago ao definido. E de modo semelhante toda evolução que conhecemos procede do vago ao definido. O futuro indeterminado torna-se passado irrevogável. $\mathrm{Na}$ frase de Spencer o indiferenciado diferencia-se. O homogêneo leva à heterogeneidade. Salvo em alguns casos especiais, portanto, devemos supor que como uma regra o contínuo tenha se derivado de um contínuo mais geral, um contínu de mais alta generalidade.

Deste ponto de vista devemos supor que o universo existente, com toda sua secundidade arbitrária, é um rebento ou uma determinação arbitrária de um mundo de idéias, de um mundo platônico; não que nossa lógica superior nos tenha capacitado a alcançar um mundo de formas para o qual o universo real, com sua lógica mais frágil, fosse inadequado.

Se isto for correto, não podemos supor o processo de derivação, um processo que se estende desde antes do tempo e da lógica, não podemos supor que ele se iniciou em algum outro lugar señ̃o na total vagueza da potencialidade completamente indeterminada e sem dimensões.

O processo evolucionário é, portanto, não uma mera evolução do universo existente, mas um processo pelo qual as próprias formas platônicas se iniciaram e se desenvolveram.

Naturalmente suporemos que a existência é um estágio evolutivo. Esta existência é presumivelmente somente uma existência especial. Não necessitamos supor que toda forma deva, para sua evolução, emergir neste mundo, mas somente que ela deva entrar em algum teatro de reacõoes, dos quais este é um deles.

A evolução das formas começa ou, de qualquer modo, tem uma vaga potencialidade para um seu estágio anterior; e que seja um continuo de formas on se faça seguir por um tal contínuo, possuindo uma multidão de dimensões suficientemente grande para que sejam distintas suas dimensões individuais. Deve ser por uma contração da vagueza da potencialidade de todas as coisas em geral, mas de nada em particular, que surgiu o mundo das formas.

Podemos somente supor que aquelas qualidades sensiveis que agora experimentamos cores, odores, sons, sentimentos de qualquer descrição, amores, pesares, surpresa - são tão-somente relíquias de um antigo contínuo de qualidades em ruinas, tal como algumas colunas mantidas de pé aqui e ali como testemunho de que neste local algum fórum de um antigo mundo com sua basilica e templos uma vez formou um magnifico conjunto. E assim como aquele fórum, antes de ser de fato edificado, tivera uma existência germinal na mente de quem planejou sua construção, do mesmo modo o cosmos das qualidades sensiveis, que deveria supor-se ser em um estágio primitivo de ser tão real quanto é a vida pessoal neste atual minuto, possuía em um estágio antecedente de desenvolvimento um ser mais vago, antes que as relações de suas dimensões tenham se tornado definidas $e$ contraidas. (CP. 6.191-197).

Adentrando ao domínio da Semiótica, a tríada volta a se reproduzir. O signo, como vários textos de Peirce o atestam, é um primeiro que substitui um segundo, seu objeto, determinando um terceiro, seu interpretante, o qual tanto quanto o signo representa o objeto mas como isto ele o faz mediante o signo, representa igualmente o segundo naqueles atributos representados pelo primeiro signo. Não fora a potencialidade do signo, suas qualidades afirmativas, jamais o objeto seria desvendado tornando-se interpretável por uma mente. Não 
fosse a potencialidade do signo o pensamento não teria lugar, nada mais restando que um confronto de forças brutas.

O pensamento, como um processo evolutivo e crescente de representação do mundo, somente tem lugar porque as qualidades consideradas em sua original espontaneidade, antes mesmo de se concretizarem em existentes, interagindo já então como existentes, ou tomando a forma geral de lei, afetam-se mutuamente e rompem a incomunicabilidade que caracteriza o objeto como algo que, por definição, se opõe a tudo que não é ele.

$\mathrm{Na}$ dedução das classes de signos que a semiótica permite levar a efeito, a potencialidade do signo estará sempre vista sob a forma de presença de qualidades afirmativas. Na relação do signo consigo mesmo, o qualissigno é a forma originária de todo signo. Um existente que é um signo constituir-se-á da concreção de diversas, senão de infinitas, qualidades cuja limitação recíproca é tomada como signo e a lei será a generalização de tais qualidades. Na relação do signo para com seu objeto dinâmico, ou objeto ao qual o signo em último lugar se refere, a relação icônica, ou aquela pela qual o signo substitui o objeto por compartilhar com ele de uma qualidade comum é valorizada por Peirce como sendo condição necessária para que todo signo represente um objeto.

Toda idéia em sua originalidade é da natureza do ícone e não há proposição ou argumento que não implique direta ou indiretamente ícones:

O único modo de diretamente comunicar uma idéia é por meio de um ícone; e todo método indireto de comunicar uma idéia depende, para que se estabeleça, do uso de um icone. Portanto, toda asserção deve conter um icone ou conjunto de icones, ou deve conter signos cujo significado somente é explicável por ícones. A idéia significada por um conjunto de icones (ou por um equivalente a um conjunto de ícones) contidos numa asserção pode ser denominada predicado da asserção. (CP. 2.278)

Como todo ícone era interpretado como signo de possibilidade, determinará um rema como seu interpretante final e, em sua originalidade pertencerá ao Mundo Interior platônico.

Tomará, pois, os existentes como concreções exemplares de idéias reconhecidas como tais pela mente interpretante. Todo reconhecimento implica pois numa instância poética, num ato criativo da inteligência. E tal reconhecimento precede qualquer representação simbólica, e por seu exercício propiciará o acesso ao símbolo como representação genuinamente geral e publicamente comunicável.

A presença do ícone encontrará sua inserção no universo da experiência através de suportes dos quais valorizará como signos o caráter de primeiridade. A signos icônicos de tal modo sustentados, Peirce denominou hipoícones (CP. 2. 276-277). Caso o caráter icônico recair sobre o hipoícone em sua relação de representamen, fazendo ressaltar a Primeiridade do 
Primeiro Correlato, o signo constituir-se-á de imagens. Se aquele caráter recair sobre a relação do signo para com seu objeto, fazendo com que a forma estabelecida no representamen apresente indicadores que permitam atribuí-la ao objeto dinâmico, estará sendo considerada a Primeiridade do Segundo Correlato, e o signo será reconhecido como diagrama. Caso a primeiridade for incidir sobre a relação do signo com seu interpretante final, estará sendo considerada a Primeiridade de Terceiridade, e se está adentrando no domínio das metáforas.

Nesta instância geral, na qual os objetos são representados genuinamente como classes de fenômenos e, por conseqüência, generalizados sob a forma de leis, a primeiridade assumirá a forma abdutiva de formulação de hipóteses.

Em seu caráter formal, a abdução é a proposta de uma representação geral que permita explicar uma determinada classe de fenômenos. Desse modo, o que pretende é produzir um raciocínio de estrita possibilidade. Sua conclusão é que se o fenômeno for explicável pela teoria proposta ele, ipso facto, adentra ao universo da racionalidade como logicamente possível. Tomará, pois, os existentes como concreções exemplares de idéias reconhecidas como tais pela mente interpretante. Todo reconhecimento implica pois numa instância poética, num ato criativo da inteligência. E tal reconhecimento precede qualquer representação simbólica, e por seu exercício propiciará o acesso ao símbolo como representação genuinamente geral e publicamente comunicável.

Geneticamente considerado, ou seja, inserido no contínuo do pensamento, o raciocínio abdutivo ou retrodutivo supõe procedimentos que o antecedam, que o solicitem e que lhe permitam efetivamente colaborar para a determinação pública da conduta racional.

A conduta racional é determinada por hábitos como expectativas de atuação sobre objetos quando ensejada pela experiência. Não havendo discrepância suficientemente grande entre as expectativas que norteiam a conduta e o atual confronto com o objeto, o hábito como consolidação da conduta é suficiente para determiná-la sem sequer dar lugar a um ato consciente. Mesmo que haja apelo à consciência, a representação que se faz do objeto e da relação que com ele deve manter a conduta para assumi-lo como a um fim pode não ser suficientemente abalada a ponto de não se poder estender ao objeto com que confronta as representações que no passado tiveram o efeito esperado quando defrontadas com objetos semelhantes. Em grande parte de nossas ações a economia trazida pelos hábitos adquiridos não precisará ser abandonada no momento do confronto com o objeto. Em conseqüêcia da pouca ou insignificante estranheza apresentada pelo objeto, nossas crenças de como com ele se não sofrerão qualquer abalo. Os processos abdutivos, em tais casos, não parecem requerer atenção especial. Diante contudo de objetos cuja excepcionalidade seja muito significativa, o processo abdutivo irá se impor como 
único meio de se procurar uma explicação racional para o fenômeno e para a condução autocontrolada da conduta.

Três importantes situações na relação de experiência devem ser, mesmo que brevemente, consideradas, as quais fazem urgir a inferência abdutiva.

A primeira situação é aquela que inaugura qualquer processo de conhecimento de natureza inferencial e que se encontra na origem da visão realista de Peirce sobre o conhecimento e a conduta. Um fenômeno acede ao limiar da consciência não por uma imposição imediata à sua representação mas por um juízo de natureza hipotética cujas premissas subjazem à primeira síntese existencial, falível, dirá Peirce, mas indubitável. A abdução originária tem lugar no juízo perceptivo num memento inseparável ao da primeira indução. Caso dele se duvide, de nada adianta, pois uma nova percepção, por mais atenciosa que seja, constituir-se-á num novo juízo perceptivo igualmente falível e indubitável.

A segunda situação é aquela em que o objeto não pode sofrer um processo de abstração e generalização tal que se submeta a uma conduta meramente habitual. O objeto, no caso, exige ser considerado em sua insubstituível singularidade e, por conseguinte, exige que para ser bem representado, dele se faça, a cada momento, uma idéia totalmente nova. Toda situação eminentemente dialogante supõe um tal cuidado. Este é o caso da relação médico-paciente, professor-aluno e, entre outros casos semelhantes, o de nós com nós mesmos.

A terceira situação é aquela, mais comumente considerada, de casos anômalos no âmbito uma representação geral. Consideram-se, neste caso, hipóteses científicas formuladas após gerações, conferindo, finalmente, uma representação pública, autoconsciente e auto-controlada a uma classe de fenômenos que desafiavam as explicações até então disponíveis.

Para a construção de hipóteses científicas, Peirce não somente afirma que as únicas regras a serem seguidas são de natureza econômica, como apresenta, no mínimo, dois tratamentos complementares para o atendimento à necessidade de se otimizar os recursos disponíveis.

Precedendo hierarquicamente a qualquer uma dessa regras, propõe Peirce um único princípio: o de que qualquer hipótese só será validada se dela decorrerem, por dedução, conseqüências verificáveis experimentalmente.

Em uma das formulações propostas para este princípio, pode-se ler:

Considerarei agora quais os princípios que nos guiariam na abdução, ou no processo de escolher uma hipótese. Subjacente a tais princípios bát uma abdução fundamental e primária, uma hipótese que devemos assumir desde o início , por mais que possa ser 
destituida de qualquer suporte de evidência. Esta hipótese é que os fatos em mãos admitem racionalização, e racionalização feita por nós. ... Devemos ser animados por esta esperança no que diz respeito ao problema que temos em mãos, o estendamos ao $\{$ ou (?)\} não como um principio geral cobrindo todos os fatos. Que aquilo de que trata uma nova verdade não possa decorrer da indução ou da dedução, nós já vimos. Só pode vir da abdução; e a abdução é, em última instância, nada mais do que conjecturar. Estamos pois atados à esperança de que, embora as possiveis explicações de nossos fatos possam ser inúmeras, mesmo assim nossa mente será capaz em algum número finito de escolhas, de escolher a sua única explicação verdadeira. A isto estamos obrigados a assumir, independentemente de qualquer evidência de que seja verdadeiro. Animados por esta esperança, devemos proceder à construção de uma hipótese. (E P.2. p. 106s.)

A primeira série de regras dá prosseguimento ao texto agora citado. Dirá que:

A economia, em geral, depende de três espécies de fatores: o custo; o valor da coisa proposta, em si mesma; e seu efeito sobre outros projetos. Sob o item custo, se a hipótese puder ser levada ao teste do experimento com pouco dispêndio de qualquer espécie, seria isso visto como uma recomendação para the dar precedência no procedimento indutivo. Mesmo que ela seja pouco admissivel por outras razões, mesmo assim ela pode clarear o fundamento por ela utilizado. ... ${ }^{108}$ Sob o item valor, devemos colocar aquelas considerações que tendem para uma expectativa de que uma dada hipótese possa ser verdadeira. Elas são de duas espécies: as puramente instintivas e as raciocinadas. No que diz respeito às considerações instintivas, já apontei que é uma hipótese primária subjacente a toda abdução de que a mente bumana é afim à verdade no sentido em que num número finito de tentativas lançará luz sobre a bipótese correta. A experiência indutiva, com efeito, dá suporte a esta hipótese numa notável medida. Pois se não howvesse uma tendência desta espécie, se, quando um fenômeno surpreendente se apresentasse em nosso laboratório, teríamos que fazer escolhas ao acaso sobre as condições determinantes, tentando tais hipóteses como se os aspectos dos planetas tivessem alguma coisa a ver com isso, on o que estaria há cinco minutos atrás fazendo a imperatriz da China, caso tais bipóteses tivessem a mesma oportunidade de serem verdadeiras quanto aquelas que parecem marcadas pelo bom senso, e nós, então, não teríamos feito qualquer progresso em ciência. Mas se encontra fora de disputa que tivemos sólidos ganhos no conbecimento; e mais ainda, a bistória da ciência prova que ao menos foi às vezes necessário tentar mais de duas ou três hipóteses por gênios esclarecidos antes que a verdadeira fosse encontrada.... Quanto à existência de um instinto natural para a verdade, trata-se, em última instância, do último recurso disponivel (sheet anchor) da ciência para se salvar. Das marcas instintivas, passamos para as marcas raciocinadas da verdade na hipótese. Naturalmente, se conhecemos alguns fatos positivos que tornam objetivamente provável uma dada hipótese, eles recomendam-na para o teste indutivo. Quando este não é o caso, mas a hipótese nos parece sugestiva ou não sugestiva, esta semelhança é uma inclinação de que a bipótese esteja de acordo ou desacordo com nossas idéias preconcebidas; e uma vez que aquelas idéias presumidamente baseiam-se sobre alguma experiência, segue-se que, outras coisas sendo iguais, haverá, no decorrer do tempo, alguma economia em fornecer um lugar para a hipótese na ordem de precedência de acordo com esta inclinação. Mas a experiência deve ser nossa carta na navegação econômica; e a experiência mostra que as semelhanças são ${ }^{109}$ guias traidores. Nada tem causado mais perda de tempo e de recursos, em todas as espécies de pesquisa, do que se tornarem os pesquisadores tão apegados a certas semelhanças a ponto de esquecerem-se de todos os outros fatores da economia da pesquisa; 
de tal modo que, a não ser que esteja muito bem fundamentada, é melhor que a semelhança não seja levada em conta, ou praticamente não o seja; e mesmo quando ela parecer solidamente fundamentada, dever-se-ia proceder com muito cuidado, tendo sempre em vista outras considerações, e levados em conta os desastres que tem causado.

A terceira categoria de fatores de economia, aqueles que surgem da relação do que é proposto com outros projetos, é especialmente importante na abdução, porque muito raramente podemos positivamente esperar que uma dada bipótese se prove inteiramente satisfatória, e devemos sempre considerar o que acontecerá quando falhar a bipótese proposta. As qualidades que essas considerações nos induzem a valorizar numa bipótese, são três, que eu posso denominar: Cuidado, Extensividade e Não-complexidade. Com respeito ao cuidado, o jogo das vinte questões é instrutivo. ... Se as questôes forem babilidosas, o objeto invariavelmente será atingido; mas se quem pergunta se deixar enredar por preconceitos, eles quase que infalivelmente fracassarão. ... Se cada questão exatamente bissecionasse as possibilidades, de maneira que sim ou não fossem igualmente prováveis, o objeto certo poderia ser identificado no interior de uma coleção de $2^{20}$ [caso se considere que o conjunto dos objetos comumente conhecidos não ultrapassa $\left.10^{6}\right]$... O segredo do negócio está no cuidado de dividir a hipótese em seus mais simples componentes lógicos, e somente arriscar um deles de cada vez. ..... ${ }^{110}$

Correlativa à qualidade do cuidado é a qualidade da extensividade. Pois quando partimos a hipótese em suas partes elementares, podemos e deveríamos investigar até que ponto a mesma explicação dá conta do mesmo fenômeno quando ele aparece em outros sujeitos. ... É, pois, de boa economia, outras coisas permanecendo iguais, tornar nossas hipóteses as mais amplas possiveis. Mas, naturalmente, uma consideração deve ser contrabalançada com as outras.

Ainda permanece uma consideração mais econômica com referência a uma hipótese; qual seja, de que ela deve deixar uma boa "saída", como dizem os jogadores de bilhar. Se ela não segue os fatos, mesmo assim a comparação com os fatos pode ser instrutiva com referência à próxima hipótese. ... Como uma hipótese provisória, será, por essa razãa, outras considerações à parte, melhor assumir alguma coisa muito simples, mesmo que imaginemos que complicando a bipótese ela seria levada mais próxima da verdade.

A segunda série de recomendações refere-se a pesquisas articuladas umas às outras constituindo um conjunto complexo de investigação. Considerando que, ao longo do tempo, o custo da pesquisa e a informação obtida variam inversamente um do outro, o custo aumentando progressivamente enquanto o acréscimo de informação irá tendendo a zero, Peirce procurar estabelecer estratégias que otimizem a correlação custo/benefício. O texto, assim, proporá:

Há, naturalmente, uma doutrina da Economia da Investigação. Um ou dois desses princípios são facilmente compreensiveis. O valor do conbecimento é, para os propósitos da ciência, em um certo sentido absoluto. Pode-se dizer que não deve ser medido pecuniariamente; e, num certo sentido, isto é verdadeiro. Mas o conbecimento que leva a outro conbecimento é mais valioso na proporção do prejuízo de que ele resguarda o investimento para se alcançar aquele outro conhecimento. Possuindo-se um certo fundo de energia, tempo, dinheiro etc., tudo isso sendo artigos negociáveis a serem gastos na pesquisa, a questão é saber quanto estará disponivel para cada investigação; e para nós o valor daquela investigação é a quantidade de dinbeiro que nos será conferida para 
gastar. Relativamente, portanto, o conhecimento, mesmo de uma espécie puramente cientifica, tem um valor monetário.

[O valor do conbecimento] cresce com a plenitude e a precisão da informação, mas cresce cada vez mais devagar na medida em que o conbecimento torna-se mais pleno e mais preciso. O custo da informação também cresce com sua plenitude e precisão, e cresce tão mais rapidamente quanto mais preciso e pleno ele for. Pode, portanto, ser o caso dele não pagar para obter qualquer informação sobre um certo assunto; mas, de qualquer modo, deve ser verdade que ele não paga (em qualquer estado dado da ciência) para levar a investigação além de um certo ponto de plenitude e precisão.

Se tivermos um certo numero de estudos que nos interessam, deveríamos comecar com o que mais remunerasse e levá-lo adiante até que ele se torne tão remunerador quanto o comeşo de um outro; levando adiante ambos na medida em que ambos forem igualmente remuneradores até que cada um deles não for mais remunerador do que um terceiro, $e$ assim por diante.

Se duas ou mais espécies de conbecimento forem de tal modo relacionadas que uma possa substituir a outra, a posse de uma tornando a outra menos lucrativa, diminuir-se-á a investigação de cada uma, enquanto cresce a investigação de todas.

Se duas ou mais espécies de informação forem úteis somente para mutuamente suplementarem-se, isto é, somente quando conjuntamente combinadas, incrementar-se-ão as investigações até que só haja pouca vantagem, ou mesmo nenhuma, da espécie de pesquisa menos remuneradora. (CP. 1.121-125).

Dado o caráter insuperavelmente hipotético de toda representação e, em especial, das teorias científicas, as estratégias da investigação expostas nas duas séries de considerações se complementam e, com freqüência, se imbricam. Não se devendo pressupor um instinto de racionalidade que movesse a razão por um inexorável sentimento de verdade, sequer podendo caber numa fundamentação última da capacidade explicativa da ciência a suposição de uma intrínseca regularidade da natureza, somente a razão com seus hábitos e sua capacidade de questionar o real por se ver por ele desafiada e atraída poderá encontrar meios para representá-lo e para dirigir seus próprios passos. Deverá, pois, ser previdente no dispêndio de seus recursos para que o fim almejado possa ser alcançado. Se o pensamento é para Peirce a construção de formas imaginárias que delineiem para o futuro os meios para alcançar o objeto, se, pois, o pensamento é, essencialmente, diagramático, ele é antes de tudo icônico, poético e corajoso para enfrentar, com os poucos recursos de que dispõe, o embate da experiência. Enfrentá-la, contudo, é preciso, pois é nela que se encontra, sob a forma do desejo, a razão de ser da própria racionalidade.

\section{Referências bibliográficas}

PEIRCE EDITION PROJECT (ed.) - The Essential Peirce. Selected Philosophical Writings. Vol. 2. (18931913). Bloomington - Indianapolis, IN: Indiana University Press, 1998. (A referência no corpo do texto se faz segundo a notação E P, vol. página ). 
PEIRCE, Charles Sanders - Collected Papers of Charles S. Peirce. Vols. 1-8. Edited by Charles Hartshorne, Paul Weiss \& Arthur Burks. Cambridge, MA: Harvard University Press, Vols. 1-6, 1931/ 1974; vols. 78, 1958. As referências seguem a seguinte convenção: CP. Correspondendo a Collected Papers; o primeiro algarismo, ao número do volume e, após um ponto, o(s) número(s) do(s) parágrafo(s). 